\title{
Poder e participaÇão
}

\author{
Felipe Corrêa*
}

Resumo O presente artigo tem por objetivo realizar uma reflexão teórica acerca do poder, apresentando a problemática envolvida nas discussões do tema e três categorias fundamentais que pretendem abarcar as distintas concepções do poder: participação, dominação e autogestão. A partir de um aprofundamento das posições de Michel Foucault e Tomás Ibáñez, que concebem o poder como assimetria nas relações de força, propõem-se um modelo teórico e um método de análise que consideram a dominação e a autogestão como tipos ideais e extremos de um eixo da participação, o que permite refletir e tipificar as relações e os modelos de poder. Utilizado o modelo proposto, analisam-se o capitalismo, as classes sociais, a luta de classes e a natureza do Estado. Ao partir dos elementos teóricos explicitados, reflete-se sobre possíveis estratégias para a mudança e a transformação social, evidenciando problemáticas que envolvem os movimentos sociais.

Palavras-chave Poder; participação; dominação; autogestão.

\section{Power and PARTICIPATION}

Abstract This paper aims to conduct a theoretical reflection of power, presenting the issues involved in the discussions of the topic and three fundamental categories that are intended to cover the different conceptions of power: participation, domination and self-management. From a deepening of the positions of Michel Foucault and Tomás Ibáñez, that conceive power as asymmetry in force relations, we propose a theoretical model and a method of analysis that considers domination and selfmanagement as ideal types and extremes of an axis of participation, which allow to reflect and classify the power relationships and patterns. Using the proposed model, we analyze capitalism, social classes, class struggle and the nature of the state. Based on the explicit theoretical elements, we reflect on possible strategies for social change

Recebido para publicação em 30/01/2012.

Aceito para publicação em 18/10/2012.

* Mestrando do Programa Mudança Social e Participação Política da Escola de Artes, Ciências e Humanidades da Universidade de São Paulo. 
and transformation, highlighting issues that involve social movements.

Keywords Power; participation; domination; self-management.

\section{INTRODUÇÃO}

Ainda que o poder seja um tema constantemente presente nas ciências sociais, aportes contemporâneos vêm aprofundando suas definições e a compreensão de seu funcionamento e contribuindo de maneira determinante para os métodos de análise sociais, tanto da institucionalidade quanto de fora dela. O presente artigo propõe: 1. conceituar o poder, identificar onde ele se manifesta e explicitar como ele funciona; 2. apresentar um modelo para tipificar, classificar e analisar as distintas relações de poder, fundamentando-se na participação; 3. contribuir com aportes teóricos às reflexões contemporâneas sobre o Estado, as classes sociais e os movimentos sociais. Para tanto, utiliza-se uma abordagem interdisciplinar, com autores de diferentes áreas acadêmicas, pois, assim, os objetos poder e participação podem ser melhor compreendidos e estudados.

\section{O PODER: DEFINIÇÃO, LOCUS E MODUS OPERANDI}

Discutir o poder implica, necessariamente, superar o problema semântico que há em toda a extensa literatura que historicamente aborda o tema. Buscando algumas definições, encontra-se: poder é “toda probabilidade de impor a própria vontade numa relação social, mesmo contra resistências, seja qual for o fundamento dessa probabilidade" (WEBER, 2009, p. 36); “em seu significado mais geral, a palavra poder designa a capacidade ou a possibilidade de agir, de produzir efeitos" (BоввIо, 2004, p. 933); “o poder é [...], acima de tudo, uma relação de força” (FouCAult, 2005, p. 175); "designamos por poder a capacidade de uma classe social de realizar os seus interesses objetivos específicos" (Poulantzas, 1977, p. 100); “o poder pode ser definido como a produção dos resultados pretendidos” (Russell, 1979, p. 24). E ainda muitas outras poderiam ser citadas.

Para uma definição de poder, portanto, a questão não exige apenas adotar uma ou outra significação, mas compreender, histórica e sociologicamente, como o conceito de poder vem sendo trabalhado pelos diversos autores e quais são os aspectos e os elementos fundamentais abordados. Tal estudo exige, ao mesmo tempo, ter em mente que, por meio do mesmo termo, podem estar sendo discutidas distintas questões e, por outros termos - como, nesse caso específico, autoridade e dominação -, podem estar sendo discutidas as mesmas questões. Trata-se, assim, 
de compreender amplamente o objeto em questão e suas distintas abordagens, considerando as referidas precauções metodológicas. Tomás Ibáñez (1982, p. 11) ${ }^{1}$ enfatiza parte dessa problemática envolvida nos estudos sobre o poder:

O fato de os pesquisadores das relações de poder seguirem, depois de tantos anos, dedicando parte importante de seus esforços para esclarecer e depurar o conteúdo da noção de poder, o fato de não haver um acordo minimamente generalizado sobre o significado desse termo e o fato de as polêmicas se darem mais sobre as diferenças de conceituação do que sobre as operações e resultados conseguidos a partir dessas conceituações, tudo isso indica claramente que a teorização sobre o poder encontra-se, em algum momento, com um obstáculo epistemológico que a impede de progredir.

Superar esse obstáculo implicaria, para Ibáñez, compreender o conteúdo das discussões em questão e avançar em relação a elas, no que se refere àquilo que denomina como "analítica do poder". Considerando as mais distintas definições de poder, o autor considera ser possível agrupá-las a partir de três grandes interpretações: 1. do poder como capacidade, 2. do poder como assimetria nas relações de força; e 3. do poder como estruturas e mecanismos de regulação e controle.

Numa das suas acepções, provavelmente a mais geral e diacronicamente primeira, o termo "poder" funciona como equivalente da expressão "capacidade de", isto é: como sinônimo do conjunto dos efeitos dos quais um agente dado, animado ou não, pode ser a causa direta ou indireta. É interessante que, desde o início, o poder se define em termos relacionais, na medida em que, para que um elemento possa produzir ou inibir um efeito, é necessário que se estabeleça uma interação. [...] Numa segunda acepção, o termo "poder" refere-se a um certo tipo de relação entre agentes sociais, e costuma-se agora caracterizá-lo como uma capacidade assimétrica ou desigual que os agentes possuem de causar efeitos sobre o outro pólo de uma dada relação. [...] Numa terceira acepção, o termo "poder" refere-se às estruturas macro-sociais e aos mecanismos macro-sociais de regulação ou de controle social. Fala-se, neste sentido, de "instrumentos" ou "dispositivos" de poder, de “centros” ou de "estruturas” de poder, etc. (IbáÑ̃Z, 2007, p. 43-44).

1 Em Poder y liberdad, sua tese de doutoramento, Ibáñez analisa profundamente o poder, a partir de mais de trezentas obras. 
Essas três conceituações do poder colocam-no no campo das relações sociais, e, por isso, excluem-se tanto as relações entre pessoas e coisas/animais - considerando que as relações de poder ocorrem sempre entre humanos que vivem em sociedade - quanto as relações que poderiam ser constituídas sem sujeitos.

Conceituar o poder como capacidade implica concebê-lo como "ter poder de fazer algo" ou "ter poder para algo"; o poder, assim, define-se a partir de uma capacidade de realização ou uma força potencial que poderia ser aplicada em uma relação social determinada. Compreender o poder como assimetria nas relações de força implica um conceito que, ainda que esteja ancorado na noção de capacidade explicitada na primeira acepção, não pode se resumir a ele. Nesse caso, o cerne da definição está nas assimetrias das diferentes forças sociais que se encontram em determinada relação social; quando essas forças, com capacidades distintas de causar efeitos sobre outras, põem-se em interação, forjam os efeitos sobre um ou mais polos da relação. Conceber o poder como estruturas e mecanismos de regulação e controle significa conceituá-lo a partir do conjunto de regras de determinada sociedade, que envolve tanto as tomadas de decisão para seu estabelecimento e para definir seu controle quanto a própria aplicação desse controle; uma estruturação social que exige instâncias deliberativas e executivas.

A obra de Michel Foucault, um dos pilares teóricos de Ibáñez, apresenta uma conceituação do poder que, ainda que o defina em termos de relação de força, articula-se com as noções de capacidade e de regulação e controle; ela permite uma abordagem ampla, abarcando elementos das três interpretações prévias. Para Foucault (2005, p. 176), "as relações de poder nas sociedades atuais têm por base essencialmente uma relação de força estabelecida, em um momento historicamente determinável"; forças que estariam em disputa, em luta permanente, em correlação e em um jogo contínuo e dinâmico. Quando, em uma determinada correlação de forças, alguma delas se impõe em relação às outras, há uma relação de poder. "As relações de poder são uma relação desigual e relativamente estabilizada de forças" (Foucault, 2005, p. 250). Assim, poder e relação de poder se tornam sinônimos. Ibáñez, a partir de Foucault, conceitua o que denomina "paradigma estratégico do poder" da seguinte maneira:

O poder é uma relação, um ato. O poder é algo que se exerce. O poder tem uma presença difusa em toda a estrutura social, se produz em todo lugar do social. É onipresente não porque chega a todos os lugares, mas porque brota de todas as partes. [...] O poder toma a forma dos modelos da física. O poder é consubstancial com o social, não existem, assim, zonas sem poder, ou que escapem ao seu 
controle. O poder é imanente aos domínios em que se manifesta, a economia está constituída por relações de poder que lhes são próprias. O poder é ascendente, os poderes locais vão delineando efeitos de conjunto que conformam os níveis mais gerais: modificando as relações de força locais modificam-se os efeitos do conjunto. [...] O poder é, antes de tudo, uma instância produtiva. O poder produz saber, engendra procedimentos e objetos de saber. Quem ocupa uma posição de poder produz saber. O poder resulta de uma vitória; tem a guerra por origem. Os mecanismos do poder são da ordem do controle e da regulação, da gestão e da vigilância. [...] O poder não funciona a partir do soberano, mas a partir dos sujeitos. A vida é o símbolo do poder, seu objetivo é gerir e administrar a vida (IBÁÑ̃Z, 1982, p. 99-100).

A partir de Foucault e Ibáñez, pode-se conceituar o poder como uma relação social concreta e dinâmica entre diferentes forças assimétricas, em que há preponderância de uma(s) força(s) em relação à(s) outra(s). O poder se encontra em todos os níveis e todas as esferas da sociedade e fornece as bases para o estabelecimento de regulações, controles, conteúdos, normas, sistemas que possuem relação direta com as tomadas de decisão.

\section{PARTICIPAÇÃO: DA DOMINAÇÃO À AUTOGESTÃo}

A participação é estabelecida a partir das relações de poder. Alfredo Errandonea (1989, p. 122) define a participação como "a capacidade de incidência e iniciativa própria nas decisões que lhes afetam, pessoal, grupal ou coletivamente. Todo tipo de decisões: no sentido mais amplo". Assim, as decisões relativas às esferas da sociedade (econômica, política/jurídica/militar, cultural/ideológica) seriam forjadas a partir de distintos níveis de participação, compreendendo “os mais diversos acessos vinculados à própria atividade, coletivamente integrada ou não” (ERRANDONEA, 1985, p. 10). Se, como se viu, regulações, controles e normas constituem-se a partir das relações de poder, estas também constituem as bases da participação.

Teorizar sobre a participação a partir das relações de poder implica, portanto, concebê-la como um campo político ampliado, para além do âmbito do Estado e envolvendo as distintas esferas sociais.

Pode-se dizer que o campo da participação possui dois extremos, que funcionam como tipos ideais de poder: a dominação e a autogestão. A dominação é uma relação social hierárquica que pode ocorrer em todas as esferas da sociedade 
e institucionalizar-se com uns decidindo aquilo que diz respeito a outros e/ou a todos. Ela explica as desigualdades estruturais, envolve relação de mando/obediência entre dominador/dominado, alienação do dominado, entre outros aspectos. É o fundamento básico das relações de classes, ainda que não se possa reduzir dominação à dominação de classe (ERrANDONEA, 1989, p. 63-82). A autogestão é o oposto da dominação e implica participação no planejamento e nos processos decisórios, proporcionalmente ao quanto se é afetado por eles, de forma pessoal, grupal ou coletiva, nas diferentes esferas. Sua aplicação generalizada implica a substituição de um sistema de dominação por uma sociedade igualitária/libertária (Albert, 2004, p. 17-26; ERrandonea, 1989, p. 122).

No limite, a participação máxima generalizada [que se está chamando aqui de autogestão] que consegue substituir totalmente a dominação, reduzindo-a à inexistência, implicaria uma sociedade igualitária e libertada, segundo esta maneira de concebê-la. No outro extremo, também no limite, em termos lógicos, poderia dizer-se que a participação reduzida a zero, a sua total inexistência, integralmente substituída pela dominação, significaria uma sociedade de escravidão absoluta, se é que ela possa ser possível. Ao contrário do que acontece com o outro limite, para o qual não há inconveniente em concebê-lo - seja ele realmente possível ou não - este extremo que representa a absoluta robotização da conduta humana, ainda que seja logicamente concebível, parece nunca ter existido e até impossível de ser concebido como possibilidade real. Parece impensável a situação de um ser humano ser privado até de suas mínimas capacidades de iniciativa; isso constituiria um nível de dominação inútil para o próprio dominante (ERRANDONEA, 1985, p. 10-11).

Os extremos constituídos pela dominação e pela autogestão demarcam, teoricamente, as possibilidades lógicas de limites nos processos de participação. Independentemente da possibilidade real ou não de se chegar a um dos tipos ideais, esses extremos, é relevante concebê-los como um modelo teórico lógico para a compreensão das diferentes relações de poder, dos tipos dessas relações e das distintas formas de participação que delas derivam. Esse esquema teórico abarca desde situações cotidianas, resultado dos micropoderes, até situações mais amplas e estruturais, constituídas pelos macropoderes. Assim, conceber as relações de poder dentro desses dois extremos, a partir do eixo da participação, constitui um método de análise para relações nos distintos níveis. 
No limite da dominação, os agentes sociais não possuem capacidade de incidência, nem iniciativa para as decisões que lhes afetam; no limite da autogestão, eles têm a maior incidência e iniciativa possíveis, participando amplamente dos processos decisórios que lhes dizem respeito. Entretanto, esses extremos só funcionam como limites teóricos para se pensar as situações reais e concretas, que, na imensa maioria dos casos, não se situam nos extremos, mas em posições intermediárias. Ainda assim, os extremos possibilitam, em termos de método, avaliar as relações de poder em questão, além dos processos de participação por elas estabelecidos. O aumento ou a diminuição da participação nas decisões permitem avaliar em que sentido caminham as relações de poder e se elas se aproximam mais de um ou de outro extremo.

A partir desse modelo teórico, avaliar as situações mais fundamentais, em termos de micropoderes, torna-se uma tarefa mais simples do que se refletir acerca dos macropoderes, forjados por uma infinidade de relações. Em ambos os casos, é difícil - para não dizer impossível - trabalhar com a categorização binária, dominação ou autogestão; além disso, em razão de a legitimidade constituir o principal fundamento das relações de poder (ERRANDONEA, 1989, pp. 126-127), surgem outros fatores que complicam a análise: a participação limitada pode servir para legitimar a dominação; a participação pode ser percebida, mas não realizada de fato, e assim por diante. Trata-se, assim, de buscar compreender teoricamente a realidade, a partir das distintas forças em jogo e das relações de poder forjadas entre elas e tentar, independentemente da percepção dos distintos agentes sociais, aproximá-las desses tipos ideais.

Pode-se dizer, por exemplo, que, em uma pequena cooperativa autogestionária, há mais autogestão que dominação e que, em um agrupamento restrito de militares, há mais dominação que autogestão. No primeiro caso, a participação é mais significativa que no segundo e é resultado das relações sociais forjadas a partir de tipos distintos de poder; na cooperativa, pode-se dizer que o poder é mais autogestionário que entre os militares, cujo poder é mais dominador (LóPEz, 2001, p. 121-130).

Entretanto, avaliar a sociedade contemporânea, por exemplo, em termos das relações sociais, levada a cabo por inúmeras forças nas distintas esferas, é tarefa mais complexa. Seria possível, em termos das macrorrelações de poder, aproximá-las dos tipos de poder mencionados? 


\section{SISTEMA DE DOMINAÇÃO, ESTADO E CLASSES SOCIAIS}

Cada sociedade é um sistema, e "suas partes estão inter-relacionadas de tal maneira que o que acontece em uma delas possui alguma repercussão nas partes restantes, claramente, em grau variável” (ERRANDONEA, 1989, p. 90). Em um sistema, as partes que o compõem dispõem-se, reciprocamente, como seus próprios elementos, e, nesse aspecto, cada sistema constitui-se a partir de uma estrutura caracterizada por uma configuração do conjunto das relações de poder existentes.

Assim, a sociedade constitui um sistema com determinada estrutura: são as forças sociais - conglomerados grupais, com interesses coletivos (geralmente, uma situação comum de classe), com certo grau de capacidade e de vontade para atuar na busca desses interesses, que atuam efetivamente, de maneira consciente, em função dos interesses, o que lhes confere a condição de fator do processo social em uma conjuntura específica (ERRANDONEA, 1989, p. 118) - que, na correlação entre si, constituem as relações de poder e determinam os elementos estruturais e a relação entre esses elementos, que constituem a estrutura de determinado sistema.

A partir dessa caracterização, Errandonea afirma que sistemas caracterizados pela dominação nos distintos níveis devem ser denominados "sistemas de dominação”, os quais são caracterizados por diferentes tipos de dominação, tais como: exploração - apropriação do sobreproduto do trabalho realizado (mais-valia) -; coação física - monopólio da violência -; e político-burocrática - monopólio das tomadas de decisões que afetam a sociedade de maneira geral (ERrANDONEA, 1989, p. 97). Nos sistemas de dominação, as estruturas sociais são estruturas de classes - as classes sociais e seu papel estrutural são os principais aspectos de sua estrutura social. Um sistema de dominação constitui, assim, um modelo de poder dominador, analisado a partir das macrorrelações sociais.

A partir dessa conceituação de sistema de dominação, não se definem a dominação e as próprias classes sociais somente a partir da esfera econômica. A exploração, por exemplo, relação social essencialmente econômica, do campo do trabalho, constitui um tipo de dominação. Ela permite dividir a sociedade em exploradores - capitalistas que se apropriam do trabalho dos trabalhadores - e explorados - trabalhadores cujo trabalho é apropriado pelos capitalistas. Entretanto, Errandonea sustenta que o sistema de dominação também é caracterizado por outros tipos de dominação, como a coação física e a dominação político-burocrática. Esses tipos de dominação permitem dividir a sociedade entre aqueles que detêm o monopólio da violência e das tomadas de decisão e aqueles que não 
o fazem. O Estado, que envolve Governo, Judiciário e militares, é um elemento central do sistema de dominação.

Pode-se definir, conforme Errandonea (1989, p. 97-119), as classes sociais a partir da dominação, extrapolando as definições que se fundamentam na exploração e que são, portanto, essencialmente econômicas - definidas, por exemplo, exclusivamente a partir da propriedade dos meios de produção.

O capitalismo contemporâneo caracterizar-se-ia como um "sistema de dominação”. Por meio da dinâmica do poder defendida por Foucault (2005, p. 25-29) - que rechaça as noções de progresso e evolução da sociedade e de determinismo econômico necessário e obrigatório (FoucAult, 2005, p. 115) e que afirma uma constituição do social a partir de distintas relações de poder conformadas em todas as esferas estruturadas da sociedade, as quais se influenciam e dependem uma da outra -, pode-se afirmar que o sistema de dominação atual, na realidade, não é um simples reflexo das relações da esfera econômica. Ele se constitui a partir da interdependência das esferas econômica, política/jurídica/militar e cultural/ ideológica, que se influenciam mutuamente (RochA, 2009). Portanto, o Estado, a partir dessas premissas, não é somente uma estrutura política que reproduz as relações das classes sociais levadas a cabo na esfera econômica; constitui-se, mais especificamente, como consequência das dominações em outras esferas, mas também como causa dessas dominações.

No campo socialista, foram os anarquistas que mais avançaram no sentido de constituir uma teoria do Estado, conforme sustenta René Berthier (2011, p. 114):

Em sua teoria do Estado, Marx e Engels não irão, contudo, mais longe do que o reconhecimento da autonomização relativa do Estado. Bakunin irá mais longe. Considerando como aceitáveis - embora permanecendo crítico - os trabalhos econômicos de Marx, pode-se dizer que Bakunin começa a análise do Estado lá onde Marx detém-se. Desmentindo as insinuações concernentes a seu desprezo pelos problemas econômicos, Bakunin funda em Estatismo e anarquia sua teoria do Estado moderno sobre a análise de desenvolvimento do capitalismo.

Para Bakunin (2003), haveria, historicamente, um encadeamento dos fatos econômicos e políticos. Ainda que com uma autonomia relativa, o Estado teria sido fundamental para o desenvolvimento do capitalismo, por razão da centralização e da sujeição do povo, que tinha a ilusão de estar sendo nele representado. Se por um lado o Estado representa os interesses dos proprietários capitalistas, por outro, constitui a estrutura política imprescindível para o desenvolvimento do capitalismo. 
Ainda que modificadas as relações de produção, se o Estado continuasse a existir, ele recriaria o capitalismo.

Pode-se, com isso, afirmar que "o Estado não é um órgão reacionário porque é a burguesia que o dirige, ele o é por sua própria constituição: o Estado é a organização de classe da burguesia” (BERTHIER, 2011, p. 115). Qualquer transformação social do capitalismo, como no caso daquela preconizada por Bakunin, que defendia o socialismo, só poderia ser realizada a partir de fora das instâncias do Estado e contra ele, já que o Estado serviria, fundamentalmente, para manter o sistema de dominação capitalista.

Seria uma organização do conjunto das classes dominadas que, a partir de seus próprios organismos econômicos e políticos, como sindicatos, movimentos sociais, etc., deveriam levar a cabo tanto a luta pela transformação quanto a estruturação de uma nova sociedade que não se pautasse em um poder dominador, mas em um poder autogestionário, acabando com a dominação de maneira geral. Ainda que ganhos de curto prazo pudessem ser conquistados, tanto na esfera econômica (melhores salários, menos horas de trabalho) como na política (maiores liberdades e direitos civis), eles deveriam ser somente meios para um processo mais amplo de transformação, capaz de forjar um poder autogestionário que suprimiria o capitalismo e o Estado, e forjaria uma nova estrutura de poder, envolvendo local de trabalho e moradia.

Com essa concepção da natureza do Estado - assumida por Errandonea (1989), ao considerar o Estado uma das bases fundamentais do sistema de dominação -, estabelece-se uma noção de classes e da própria luta de classes a partir da categoria dominação, a qual, como visto, abarca a exploração. Isso implica que a estrutura de classes não seja definida “em termos simplesmente 'econômicos”, a partir das relações de produção e exploração; as classes deveriam ser definidas a partir de uma noção mais ampla, de dominação, considerando tanto a "propriedade injusta dos meios de produção" como "a propriedade injusta dos meios de coerção - a capacidade de impor decisões fisicamente - e dos meios de administração - os instrumentos que governam a sociedade”. Atualmente, as forças armadas, os tribunais e as prisões constituiriam a base dos meios de coerção, e a burocracia do Estado, a base dos meios de administração (VAN DER WALT, 2011, p. 30).

Nessa correlação íntima entre economia e política, forja-se uma noção de estrutura de classes cindida entre classes dominantes - as quais exercem ou possuem a titularidade da dominação - e classes dominadas - tanto aquelas que estão integradas e são essenciais ao funcionamento do sistema, podendo participar na instrumentação da dominação, quanto aquelas que não estão integradas no 
sistema e não seriam completamente essenciais a ele (ERRANDONEA, 1989, p. 104). No amplo campo das classes dominantes, estariam tanto os proprietários dos meios de produção, incluindo os capitalistas e proprietários de terras, como os gestores do capitalismo, do Estado, a tecnocracia e os militares de primeiro escalão, juízes e parlamentares em geral. Entre as classes dominadas, estariam os trabalhadores, o campesinato e os precarizados e marginalizados de maneira geral (SCHMIDT; VAN DER WALT, 2009, p. 56-60, p. 108-113; vAN DER WALT, 2011, p. 31).

Portanto, o sistema de dominação e sua estrutura de classes constituem os fundamentos de uma luta de classes entre classes dominantes e dominadas; o Estado faz parte da estrutura de classes e constitui-se como o instrumento político do capitalismo, imprescindível tanto em sua criação como em sua manutenção. Constitui-se como resultado de relações de dominação e como fundamento do poder dominador que é hegemônico no capitalismo contemporâneo.

\section{PODER, LUTA DE CLASSES E ESTRATÉGIAS DE PARTICIPAÇÃO}

A definição de poder elaborada a partir das obras de Ibáñez e Foucault afirma que o poder envolve as relações sociais, estabelecendo-se como relação forjada pela superação de algumas forças por outras. "As relações de poder são consubstanciais ao próprio fato social, são-lhe inerentes, impregnam-no, contém-no, no próprio instante em que dele emanam" (IвÁÑEZ, 2007, p. 44). Não se pode conceber sociedade sem poder, independentemente de ele ser definido em termos de capacidade, assimetria nas relações de força ou estruturas e de mecanismos de regulação e controle. Qualquer sociedade possui relações sociais, agentes com distintas capacidades de realização, disputas e conflitos, aplicação de forças individuais e coletivas nessas disputas e nesses conflitos e estabelecimento de regulações e controles, mais ou menos institucionalizados, ou mesmo forjados pelo costume. O poder, portanto, está e estará presente em qualquer sociedade com relações sociais - tanto em termos micro quanto macrossociais.

Entretanto, como visto, o poder pode variar amplamente. Os tipos ideais apresentados, dominação e autogestão, extremos de um eixo de participação, servem tanto como paradigma analítico quanto como elementos para a elaboração de estratégias políticas e constituem as bases de dois modelos de poder distintos, conceituados por López: o poder dominador e o poder autogestionário. Analisado a partir desses tipos ideais, o capitalismo contemporâneo constitui um modelo de poder que é muito mais dominador do que autogestionário. Quando Errandonea o caracteriza como um sistema de dominação, fundamenta-se na análise de que, 
mesmo possuindo elementos de participação como as eleições para representantes do Estado, suas relações se aproximam mais da dominação do que da participação ampla ou autogestão.

Os fundamentos desse poder dominador, caracterizado pelo sistema de dominação, seriam as instituições que lhes são centrais e que estão presentes nas três esferas anteriormente especificadas. Por meio da análise de Rocha, que considera a interdependência e a interinfluência dessas esferas, e pela definição da natureza do Estado que Berthier elabora a partir da obra de Bakunin, pode-se afirmar que esse poder constitui-se a partir de uma relação complexa entre distintos elementos sistêmicos, entre eles o Estado - instituição política central do capitalismo.

A estrutura de classes que compõe o sistema de dominação capitalista - caracterizado por um modelo de poder mais dominador que autogestionário - permite, de acordo com Errandonea, uma análise das classes e de suas relações. Haveria, nesse sentido, dois amplos conjuntos: as classes dominantes e as classes dominadas; o modelo de poder dominador estabelecido entre eles implica interesses distintos e em permanente contradição. Os conflitos gerados a partir da contradição entre dominadores e dominados, no contexto de uma relação social sistêmica, constitui a luta de classes.

Essa análise permite reflexões sobre diferentes estratégias para a mudança ou a transformação social. Conforme afirma Clausewitz (2010, p. 171), em qualquer estratégia, são os objetivos que condicionam as ações, ou seja, os objetivos estratégicos implicam uma estratégia coerente com ele, que se desdobre em táticas, as quais devem apontar para a estratégia e esta para o objetivo estratégico. Essa questão é fundamental, pois, se o objetivo estratégico for realizar ajustes dentro de um mesmo modelo de poder, algumas formas de participação política funcionarão mais do que outras; se o objetivo for a transformação do modelo das relações de poder em nível macrossocial, outras formas de participação política serão mais adequadas.

O modelo de poder atual pode ser ajustado em benefício das classes dominadas, conjunto que hoje sofre de maneira mais direta os efeitos do sistema forjado por ele. Entretanto, os ajustes - entre os quais há alguns significativos para as classes dominadas - que são realizados como desdobramentos de uma estratégia restrita que tem por objetivo a mudança social dentro dos marcos do capitalismo não são suficientes para uma transformação do sistema de dominação e do modelo de poder. Esses ajustes, quando realizados pelo Estado, tendem a reforçar seu poder, criando uma legitimidade que é sempre muito mais eficaz para isso que a utilização da força (ERrandonEA, 1989, p. 76-77). As ações que partem do Estado - como no 
caso das políticas públicas - são, assim, táticas que se inserem em uma estratégia restrita de trabalho dentro dos marcos do Estado e, portanto, do capitalismo. São, assim, ações efetivadas pelas classes dominantes para solucionar problemas que possuem implicação direta na legitimidade do sistema que as coloca em tal posição. Em caso de sucesso, ações de Estado podem promover a mudança social, mas não a transformação social, que implicaria mudança no sistema e no modelo de poder vigentes. Isso não significa, entretanto, que todas as medidas de curto prazo favoreçam o atual sistema de dominação e tendam a fortalecer o modelo de poder dominador.

Efeitos relevantes da sociedade de classes são os movimentos sociais, definidos por Doug McAdam, Sidnei Tarrow e Charles Tilly (2009, p. 21) como uma “interação sustentada entre pessoas poderosas e outras que não têm poder: um desafio contínuo aos detentores de poder em nome da população cujos interlocutores afirmam estar ela sendo injustamente prejudicada ou ameaçada por isso". Assim concebidos, os movimentos sociais são organizações formadas pelas classes dominadas para resistir à dominação e modificar as relações de poder estabelecidas. Na maior parte dos casos, possuem objetivos restritos em torno de conquistas de curto prazo: aumento de salário e menos horas de trabalho (no caso do movimento sindical), terra e condições para a agricultura familiar no campo (no caso do movimento dos sem-terra), moradia digna (movimento dos sem-teto), melhorias para o bairro (movimento comunitário), etc. Entretanto, alguns movimentos sociais têm por objetivo estratégico uma transformação social mais ampla.

Diferentemente do Estado, uma instituição que é central para o atual sistema de dominação e faz parte de seu núcleo duro, os movimentos sociais são, historicamente, espaços de articulação das classes dominadas para a atuação em seu próprio favor. Se, por um lado, as medidas de curto prazo que partem do Estado tendem a reforçar sua legitimidade e, portanto, o sistema do qual ele constitui parte essencial, as conquistas de curto prazo provenientes da luta de classes efetivada pelos movimentos sociais podem servir para fortalecer um projeto de poder distinto, que se contraponha ao modelo vigente.

Ainda que constituam historicamente esse espaço organizativo das classes dominadas, sabe-se que os movimentos sociais, ao longo do tempo, tiveram diferentes relações com o sistema de dominação responsável por sua criação. Se houve movimentos que priorizaram o curto prazo e os ajustes nos marcos dados do poder, houve outros que, ainda que articulados para as lutas menos amplas, tiveram por objetivo uma transformação social do modelo de poder, afirmando-se como movimentos revolucionários. Em determinadas circunstâncias históricas, 
os movimentos sociais foram atrelados ao Estado - como no caso do sindicalismo brasileiro, com a legislação trabalhista de Getúlio Vargas dos anos 1930 (SAMIs, 2004). Houve também escolhas estratégicas dos movimentos que decidiram, voluntariamente, vincular-se ao Estado, fundamentalmente para o atendimento de suas demandas de curto prazo - como no caso de parte significativa do movimento de moradia de São Paulo, no início dos anos 2000 (CAVAlCANTI, 2006). Houve ainda, historicamente, leituras que compreenderam que o Estado poderia ser conquistado pelas classes dominadas e, gerido por elas, servir de instrumento para a promoção de uma transformação social. Com esse objetivo, foram criados e estimulados movimentos sociais que, mesmo atingindo seu objetivo, por uma série de fatores, não modificaram o modelo de poder vigente (TRAGTENBERG, 2007).

Todas essas questões que tratam das relações íntimas entre Estado e movimentos sociais envolvem, necessariamente, o tema da burocratização dos movimentos sociais (CoRrêA, 2011a; 2011b).

Modificar o modelo de poder da sociedade, levando o eixo da participação ao limite da autogestão, constitui um objetivo estratégico ambicioso. Substituir o sistema de dominação por um sistema de autogestão exige, em coerência com esse objetivo estratégico, estratégias e táticas que apontem para esse caminho. Táticas e estratégias que fortaleçam as relações de dominação não podem apontar para objetivos pautados na autogestão. Os movimentos sociais podem constituir espaços privilegiados para tanto, mas suas estratégias e táticas têm de estar ajustadas para tais objetivos.

As transformações sociais amplas só podem ocorrer a partir das construções cotidianas, partindo dos níveis mais básicos da sociedade. A organização autogestionária dos movimentos sociais - que envolve decisões compartilhadas em relação ao planejamento e aos processos decisórios - torna-se, portanto, um meio fundamental, senão imprescindível, para que se construa um modelo de poder autogestionário, que possa contar com os ganhos de curto prazo para o acúmulo de força das classes dominadas. Esses ganhos, entretanto, não podem se furtar de um objetivo estratégico que, mesmo sendo de longo prazo, deve nortear o fortalecimento de um modelo de poder que se contraponha ao atual e que possa alicerçar as bases da autogestão e impulsionar um processo de transformação social amplo, por meio de conquistas concretas, nas distintas esferas (melhoria de condições econômicas, maior participação política, etc.) e da construção subjetiva que poderá fortalecer culturas e ideologias próprias das classes dominadas e potencializar a vontade dos agentes envolvidos. 
Esse projeto de longo prazo exige uma superação, dentro dos movimentos sociais, das posições essencialmente de curto prazo e as demandas corporativas, de seu próprio setor. Por isso, superar os objetivos de curto prazo e promover uma integração dos movimentos sociais em prol de um objetivo de transformação mais amplo torna-se peça-chave nesse processo, sendo necessária, para isso, uma estrutura orgânica mais ampla, articulada em uma organização popular intersetorial, ou em um tipo de "frente de classes dominadas", que possam constituir o cerne da transformação social rumo a um modelo de poder autogestionário.

\section{REFERÊNCIAS BIBLIOGRÁFICAS}

Albert, Michael. Buscando a autogestão. In: Albert, Michael; Chomsky, Noam; Ortellado, Pablo; Bookchin, Murray; Guillén, Abraham (Org.). Autogestão hoje: teorias e práticas contemporâneas. São Paulo: Faísca, 2004.

Bakunin, Mikhail. Estatismo e anarquia. São Paulo: Imaginário/Ícone, 2003.

BERTHIER, René; VIlain, Eric. Marxismo e anarquismo. São Paulo: Imaginário, 2011.

Bоввіо, Norberto et al. Dicionário de política. Brasília: Editora UNB, 2004.

Cavalcantı, Gustavo C. V. Uma concessão ao passado: trajetórias da união dos movimentos de moradia de São Paulo. 148 p. 2006. Dissertação (Mestrado em Sociologia) - USP, São Paulo, 2006.

Clausewitz, Carl von. Da guerra. São Paulo: WMF Martins Fontes, 2010.

CorrêA, Felipe. Movimentos sociais, burocratização e poder popular. In: CorRÊA, Felipe. Ideologia e estratégia: anarquismo, movimentos sociais e poder popular. São Paulo, Faísca, 2011a.

. Para uma teoria libertária do poder. São Paulo: Estratégia e Análise, 2011b.

Errandonea, Alfredo. Apuntes para una teoría de la participación social. Comunidad, Estocolmo, n. 50, 1985 .

. Sociologia de la dominación. Montevideu/Buenos Aires: Nordan/Tupac, 1989.

Foucault, Michel. Microfísica do poder. São Paulo: Graal, 2005.

IBÁÑEz, Tomás. Poder y libertad. Barcelona: Hora, 1982.

Por un poder político libertario. In: IвÁñez, Tomás. Actualidad del

anarquismo. Buenos Aires: Anarres, 2007.

LóPEz, Fabio López. Poder e domínio: uma visão anarquista. Rio de Janeiro: Achiamé, 2001.

McAdam, Doug; Tarrow, Sidney; Tilly, Charles. Para mapear o confronto político. Lua

Nova, São Paulo, CEDEc, n. 76, p. 11-48, 2009.

PoulantZas, Nicos. Poder político e classes sociais. São Paulo: Martins Fontes, 1977. 
Rocha, Bruno Lima. A interdependência estrutural das três esferas. 321 p. 2009. Tese (Doutorado em Ciência Política) - UFRGS, Porto Alegre, 2009.

Russell, Bertrand. O poder: uma nova análise social. Rio de Janeiro: Zahar, 1979.

SAmis, Alexandre. Pavilhão negro sobre pátria oliva. In: Colombo, Eduardo; Colson, Daniel; Antonioli, Maurizio (Org.). História do movimento operário revolucionário. São Paulo: Imaginário, 2004.

SCHMIDT, Michael; vAN DER WALT, Lucien. Black flame: the revolutionary class politics of anarchism and syndicalism. Oakland: AK Press, 2009.

Tragtenberg, Maurício. A revolução russa. São Paulo: Faísca, 2007.

VAN DER WALT, Lucien. Debating power and revolution in anarchism, black flame and historical marxism. Johannesburg, 2011.

WEBER, Max. Economia e sociedade. Brasília: UNB, 2009. v. I e II. 